\title{
Effects of Cold Weather on Mortality: Results From 15 European Cities Within the PHEWE Project
}

\author{
Antonis Analitis \\ National and Kapodistrian University, Athens, Greece \\ Klea Katsouyanni \\ King's College London, UK \\ Annibale Biggeri \\ University of Florence, Italy
}

See next page for additional authors

Follow this and additional works at: https://arrow.tudublin.ie/scschbioart

Part of the Public Health Commons

\section{Recommended Citation}

Analitis, A., Biggeri, A. \& Baccini, M. (2008). Effects of Cold Weather on Mortality: Results From 15 European Cities Within the PHEWE Project. American Journal of Epidemiology, vol. 168, no. 12, pg. 1397-408. doi:10.1093/aje/kwn266

This Article is brought to you for free and open access by the School of Biological Sciences at ARROW@TU Dublin. It has been accepted for inclusion in Articles by an authorized administrator of ARROW@TU Dublin. For more information, please contact arrow.admin@tudublin.ie, aisling.coyne@tudublin.ie,gerard.connolly@tudublin.ie.

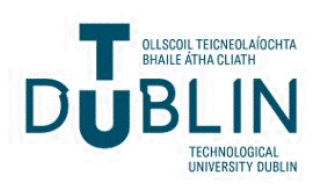




\section{Authors}

Antonis Analitis, Klea Katsouyanni, Annibale Biggeri, Michela Baccini, Bertil Forsberg Bertil Forsberg, Luigi

Bisanti, Ursula Kirchmayer, Ferran Ballester, Ennio Cadum, Patrick J. Goodman, Ana Hojs, J. Sunyer, Pekka Tiittanen, and Paola Michelozzi 


\title{
Original Contribution
}

\section{Effects of Cold Weather on Mortality: Results From 15 European Cities Within the PHEWE Project}

\author{
A. Analitis, K. Katsouyanni, A. Biggeri, M. Baccini, B. Forsberg, L. Bisanti, U. Kirchmayer, \\ F. Ballester, E. Cadum, P. G. Goodman, A. Hojs, J. Sunyer, P. Tiittanen, and P. Michelozzi \\ Initially submitted November 22, 2007; accepted for publication July 31, 2008.
}

\begin{abstract}
Weather-related health effects have attracted renewed interest because of the observed and predicted climate change. The authors studied the short-term effects of cold weather on mortality in 15 European cities. The effects of minimum apparent temperature on cause- and age-specific daily mortality were assessed for the cold season (October-March) by using data from 1990-2000. For city-specific analysis, the authors used Poisson regression and distributed lag models, controlling for potential confounders. Meta-regression models summarized the results and explored heterogeneity. A $1{ }^{\circ} \mathrm{C}$ decrease in temperature was associated with a $1.35 \%(95 \%$ confidence interval (Cl): $1.16,1.53)$ increase in the daily number of total natural deaths and a $1.72 \%(95 \% \mathrm{Cl}: 1.44,2.01), 3.30 \%(95 \%$ $\mathrm{Cl}: 2.61,3.99)$, and $1.25 \%(95 \% \mathrm{Cl}: 0.77,1.73)$ increase in cardiovascular, respiratory, and cerebrovascular deaths, respectively. The increase was greater for the older age groups. The cold effect was found to be greater in warmer (southern) cities and persisted up to 23 days, with no evidence of mortality displacement. Cold-related mortality is an important public health problem across Europe. It should not be underestimated by public health authorities because of the recent focus on heat-wave episodes.
\end{abstract}

cold; Europe; mortality; temperature; urban health; weather

Abbreviation: PHEWE, Assessment and Prevention of Acute Health Effects of Weather Conditions in Europe.

Mortality is known to be associated with meteorologic conditions and to display a seasonal pattern, with excess mortality during the winter as well as during very hot days in the summer $(1,2)$. In recent years, the effects of meteorologic factors on health have attracted renewed interest because of the observed and predicted climate change, which is expected to result in a general rise in temperature but also in abnormal climatic extremes. The short-term effects of meteorologic variables (mainly of temperature) have been studied in various locations. A J-, V-, or U-shaped association with mortality has been observed, with increased mortality at cold and hot temperatures and minimum mortality occurring at various points, depending on latitude (3-5). In the United States, various multicity studies on short-term effects of weather on mortality have been reported recently $(5,6)$. In Europe, the Eurowinter project (7) reported results from the time period 1988-1992, and a more recent multicountry project used monthly data to estimate excess winter mortality in 14 European countries (8). Increased mortality in winter is related not only to cold temperatures but also to influenza and other viral epidemics (9-11). However, the different distribution of factors that affect weather-related mortality (e.g., for winter mortality, housing and heating) can lead to major spatial and temporal differences in weather-related health effects (12). This difference points to the necessity to conduct multilocation studies and to investigate confounding and effect modification.

The Assessment and Prevention of Acute Health Effects of Weather Conditions in Europe (PHEWE) project is a multicity European effort aiming to assess short-term cold- and heat-related mortality and morbidity in 15 European cities with more than 30 million inhabitants using 1990-2000 data for 5-11 years per city. The extent of the database and the 
geographic diversity enables exploration of issues of heterogeneity and adaptation. We report here the cold-related effects on total and cause-specific mortality.

\section{MATERIALS AND METHODS}

The PHEWE database includes data from 15 European cities covering almost every geographic region of the continent. Athens, Greece; Barcelona, Spain; Budapest, Hungary; Dublin, Ireland; Helsinki, Finland; Ljubljana, Slovenia; London, United Kingdom; Milan, Italy; Paris, France; Prague, Czech Republic; Rome, Italy; Stockholm, Sweden; Turin, Italy; Valencia, Spain; and Zurich, Switzerland provided daily mortality, meteorologic, and air pollution data for 1990-2000. More details on the data are provided by Michelozzi et al. (13).

The causes of death we considered, using the International Classification of Diseases, Ninth Revision, are total mortality from all natural causes (codes 1-799) and from cardiovascular (codes 390-459), cerebrovascular (codes 430-438), and respiratory (codes 460-519) causes for all ages and by age group (0-14 for total mortality only, 15$64,65-74, \geq 75$ years). Cerebrovascular mortality data were not available in 3 cities (Athens, Paris, and Zurich) and for the age group 0-14 years in 2 cities (Athens and Barcelona). The mean daily number of deaths by cause and age group for each city is presented in Table 1 . The number of natural deaths per day ranged from, on average, 7 in Ljubljana to 179 in London. A large percentage of the deaths occurred among those older than age 75 years $(50 \%-68 \%)$, followed by deaths in the 65-74-year age group (14\%-29\%), while the counts of deaths were very small for children. Cardiovascular mortality accounted for about $40 \%-50 \%$ of the total, whereas respiratory and cerebrovascular mortality generally represented less than $10 \%$ of the total mortality counts (exceptions were London and Dublin, where respiratory deaths were responsible for up to $20 \%$ of the total).

The PHEWE database contains information about measurements taken every 3 hours of air temperature, dew point temperature, wind speed, wind direction, sea level pressure, total cloud cover, solar radiation, precipitation, and visibility. In this application, we used apparent temperature as the exposure variable, adjusting for wind speed and barometric pressure. Minimum apparent temperature is a discomfort index based on air and dew point temperatures (14). It is defined as the minimum daily value of the 3-hour apparent temperature values, calculated by using the following formula: $A T=-2.653+0.994 \times T+0.0153 \times(D T)^{2}$, where $A T$ is apparent temperature, $T$ is air temperature in ${ }^{\circ} \mathrm{C}$, and $D T$ is dew point temperature in ${ }^{\circ} \mathrm{C}$. For Barcelona, 3-hour data were not available, so mean apparent temperature was used. No data in the health time series were missing. The temperature time series had fewer than $1 \%$ missing values in all cities except Barcelona (12\%), Turin (11\%), London $(8 \%)$, and Milan $(5 \%)$, which were not imputed.

The air pollution part of the database is an updated version of the Air Pollution and Health: A European Approach (APHEA) database (15) and includes daily concentration measurements of various pollutants. Nitrogen dioxide

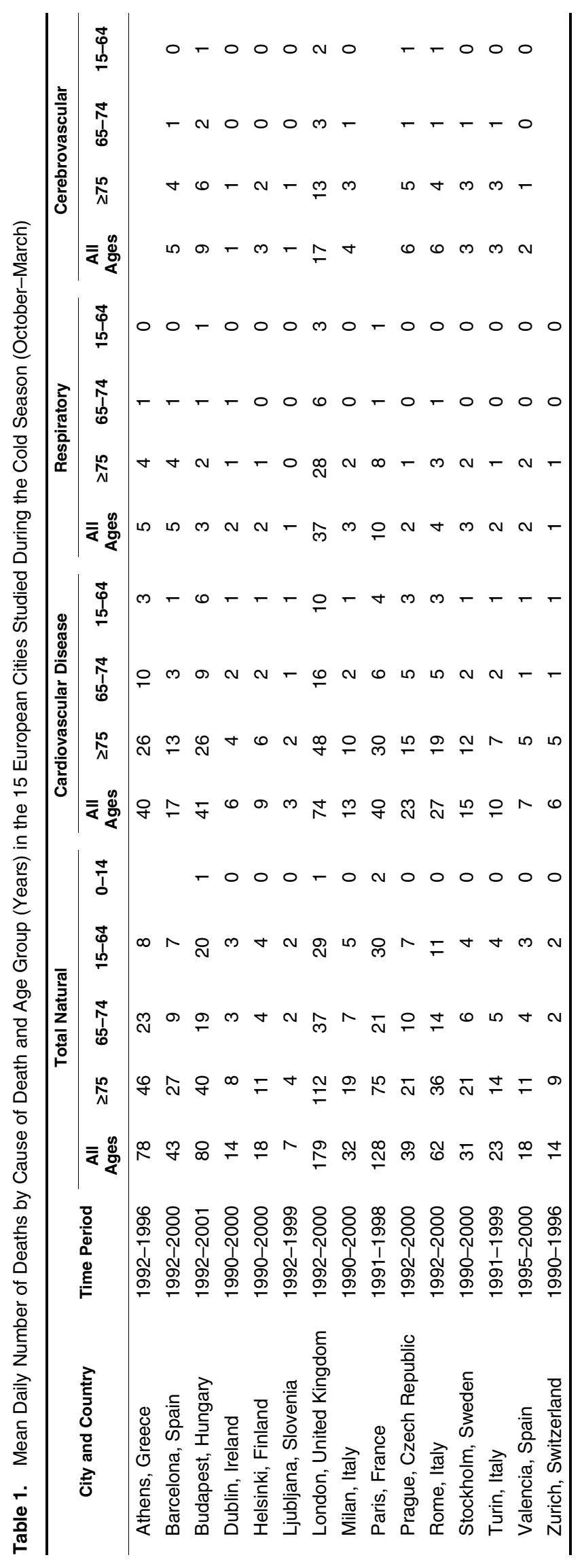


Table 2. Distribution of Minimum Apparent Temperature (Average of 16 Days) and Nitrogen Dioxide 1-Hour Maximum Level (Average of 2 Days) in the 15 European Cities Studied During the Cold Season (October-March), 1990-2000

\begin{tabular}{|c|c|c|c|c|c|c|}
\hline \multirow{2}{*}{ City and Country } & \multicolumn{3}{|c|}{$\begin{array}{l}\text { Minimum Apparent } \\
\text { Temperature, }{ }^{\circ} \mathrm{C}\end{array}$} & \multicolumn{3}{|c|}{$\begin{array}{l}\text { Nitrogen Dioxide } 1 \text {-Hour } \\
\text { Maximum, } \mu \mathrm{g} / \mathrm{m}^{3}\end{array}$} \\
\hline & $\begin{array}{c}\text { 10th } \\
\text { Percentile }\end{array}$ & Median & $\begin{array}{c}\text { 90th } \\
\text { Percentile }\end{array}$ & $\begin{array}{c}\text { 10th } \\
\text { Percentile }\end{array}$ & Median & $\begin{array}{c}\text { 90th } \\
\text { Percentile }\end{array}$ \\
\hline Athens, Greece & 3.1 & 7.5 & 17.3 & 78.0 & 112.2 & 175.7 \\
\hline Barcelona, Spain ${ }^{a}$ & 8.0 & 11.1 & 19.4 & 64.0 & 92.1 & 137.2 \\
\hline Budapest, Hungary & -6.1 & -1.5 & 7.2 & 45.5 & 80.5 & 144.0 \\
\hline Dublin, Ireland ${ }^{b}$ & -0.4 & 2.1 & 6.3 & & & \\
\hline Helsinki, Finland & -9.5 & -5.3 & 1.3 & 38.3 & 56.3 & 81.5 \\
\hline Ljubljana, Slovenia & -7.2 & -3.2 & 5.4 & 46.0 & 75.0 & 127.0 \\
\hline London, United Kingdom & -0.9 & 2.0 & 7.2 & 35.8 & 44.5 & 61.5 \\
\hline Milan, Italy & -3.6 & 0.7 & 11.0 & 102.5 & 144.5 & 238.0 \\
\hline Paris, France & -2.5 & 2.2 & 8.1 & 58.1 & 79.9 & 116.6 \\
\hline Prague, Czech Republic & -6.8 & -1.9 & 4.9 & 38.1 & 55.9 & 86.4 \\
\hline Rome, Italy & 0.3 & 4.0 & 13.2 & 71.2 & 94.3 & 131.6 \\
\hline Stockholm, Sweden & -6.9 & -3.5 & 3.0 & 30.6 & 45.7 & 61.6 \\
\hline Turin, Italy & -4.2 & -0.8 & 8.7 & 86.7 & 132.4 & 210.5 \\
\hline Valencia, Spain & 3.8 & 7.3 & 15.5 & 108.7 & 148.1 & 197.6 \\
\hline Zurich, Switzerland & -5.7 & -1.4 & 5.0 & 43.8 & 61.2 & 95.2 \\
\hline
\end{tabular}

(1-hour maximum) was chosen to adjust for air pollution. The procedures used for calculating the average values of nitrogen dioxide daily exposure measurements using data from fixed site monitors are described by Katsouyanni et al. (15). The remaining missing values per city were less than $1 \%$, except for Ljubljana (10\%), Barcelona (7\%), and Prague $(4 \%)$. Nitrogen dioxide is considered a good traffic pollution indicator, and, in the PHEWE cities, traffic is generally the major pollution source. The APHEA-2 study showed that daily mortality in (many of) the PHEWE cities depends on nitrogen dioxide levels (16). Nitrogen dioxide was also more widely and uniformly available among cities. Median values, 10th and 90th percentiles of the distribution of minimum apparent temperature, and nitrogen dioxide 1hour maximums in the 15 cities are presented in Table 2. Minimum apparent temperature varied substantially, ranging from $-5.3^{\circ} \mathrm{C}$ in Helsinki to $7.5^{\circ} \mathrm{C}$ in Athens. The median concentrations of nitrogen dioxide also varied from $44.5 \mu \mathrm{g} / \mathrm{m}^{3}$ in London to $148.1 \mu \mathrm{g} / \mathrm{m}^{3}$ in Valencia.

The analysis was carried out in 2 stages. In the first stage, individual-city data were analyzed and city-specific effect estimates were obtained, which were subsequently used in a second-stage analysis to provide overall estimates and investigate heterogeneity.

\section{Individual-city data analysis}

For the city-specific analysis, we adopted the generalized estimating equations approach (17) as an extension of generalized linear models for the analysis of longitudinal data.
For each city, we had an available outcome variable (the total or cause-specific daily number of deaths) and several covariates observed for different days. We assumed a Poisson distribution for the outcome variable. Furthermore, we assumed that the observations within each cold season (October-March) are correlated while observations in different cold seasons are independent. So, for example, winter 1992-1993, winter 1993-1994, and so forth, were considered independent. A similar approach was previously suggested by Schwartz and Dockery (18) to evaluate short-term effects of air pollution on health. Since, in our study, the number of clusters (cold seasons) was small (equal to the number of years in the study period), the robust estimator of variance, which is often optimal in a generalized estimating equations model, could be inefficient; therefore, use of the model-based variance estimator was favored. A modelbased estimator requires correct specification of the "working" correlation matrix, which was achieved by applying an exploratory analysis based on an approach similar to that described by Chiogna and Gaetan (19). Dynamic regression models (20) were combined with a genetic algorithm for semiautomated selection of the best model over a large model space, covering different specifications of the correlation structure within cluster. This analysis suggested a first-order autocorrelation structure to be appropriate.

A common model was specified for each city, taking into account potential confounders: holidays; day of the week; linear terms for barometric pressure, wind speed, and an air pollution index (nitrogen dioxide 1-hour maximum, black smoke 24-hour average for Dublin because nitrogen dioxide 
was not available); calendar month; and linear and quadratic terms for time to discern the potentially remaining longterm trend. An indicator of influenza epidemics was also included in the model (not used for respiratory events), as described by Touloumi et al. (21). Previous results have shown a prolonged effect of cold temperature on mortality $(5,22,23)$, so it was decided a priori to use as an indicator for the exposure variable the mean for the current day and the previous 15 days (lags $0-15$ ).

Because the shape of the exposure-response curve between apparent temperature and mortality was unknown, we first investigated the shape of this association. A flexible parametric approach was used to model the exposureresponse curve. We included in the generalized estimating equations model the basis vector of a cubic regression spline of apparent temperature, obtained by using the $m g c v$ library of R software (24) after defining a city-specific vector of equally spaced knots $\left(1\right.$ every $\left.8^{\circ} \mathrm{C}\right)$. The exposure-response curve was estimated for all available causes of death and age groups. After identifying the shape of the relation between minimum apparent temperature and mortality in the cold season, the city-specific effect was estimated by introducing appropriate term(s) of exposure in the model-in our case, linear terms. The final model was

$$
\begin{aligned}
\log \left(E\left[Y_{i j}\right]\right)= & {[\text { confounders }]+\sum_{k=1}^{6} b_{k} \text { month }_{k} } \\
& +b_{7} \text { day }_{i}+b_{8}\left(\text { day }_{i}\right)^{2}+b_{9} \text { temp }_{i j},
\end{aligned}
$$

where $Y_{i j}$ is the number of deaths and temp $p_{i j}$ is the value of the exposure variable on day $i$ of winter $j$.

The delayed effect (up to 30 days) of apparent temperature on mortality was investigated by using distributed lag models to avoid problems related to collinearity between lagged covariates $(25,26)$. To obtain flexibility in modeling the distribution of lags, we constrained the shape of the distributed lag curve to fit a fifth-order polynomial.

\section{Pooled analysis}

A second-stage analysis was performed to provide a quantitative summary of all individual-city results. To reduce heterogeneity, we also pooled the results by grouping the cities according to predefined meteorologic and geographic criteria. The Mediterranean cities group consisted of Athens, Barcelona, Ljubljana, Milan, Rome, Turin, and Valencia; the North-Central cities group included Budapest, Dublin, Helsinki, London, Paris, Prague, Stockholm, and Zurich.

An overall exposure-response curve was estimated by using a generalized estimating equations regression model with a cubic regression spline for minimum apparent temperature on the pooled data set (all cities). Construction of the model was similar to the city-specific one, with the addition of a city-indicator variable as well as interaction terms with confounders. This fixed-effects meta-analytical approach produces an overall descriptive exposure-response curve without pooling the individual curves, thus avoiding problems related to the large variability of the exposure ranges among cities.

To combine the city-specific effect estimates of apparent temperature on mortality, we used fixed- and random-effects meta-analysis (27). So, if $b_{i}$ is the coefficient of interest in city $i$, we assume that $b_{i} \sim \mathrm{N}\left(b, V_{i}+S\right)$, where $b$ is the summary estimate from all cities, $V_{i}$ is the estimated variance in city $i$, and $S$ is the random variance component among cities. Variables representing potential effect modifiers were introduced in second-stage regression models to investigate the causes for heterogeneity. To combine the city-specific estimates of the coefficients from the distributed lag models, we applied a multivariate random-effects regression model, as described by Berkey et al. (28).

\section{RESULTS}

Figure 1 shows the combined exposure-response curves for all natural (total), cardiovascular disease, respiratory, and cerebrovascular mortality. The curve can be adequately approximated by a linear model for all causes. The smaller counts represented by the respiratory and cerebrovascular series are reflected in the wider confidence intervals.

Figures $2-5$ show the city-specific and pooled estimated effects of apparent temperature on daily number of all natural (total), cardiovascular disease, respiratory, and cerebrovascular deaths. For all outcomes, a statistically significant effect in all 3 age groups, except for cerebrovascular causes in the age group 15-64 years, was evident, and the effect clearly increased with increasing age.

Table 3 provides the corresponding numbers for the pooled estimates shown in Figures $2-5$ and additionally the estimated pooled effects for all age groups and the effects of apparent temperature on total mortality among children using fixed- and random-effect models. The effect of cold on mortality was statistically significant for all but 1 cause and age group. Most of the estimates were heterogeneous among cities.

Table 4 shows the estimated pooled effects of apparent temperature on cause-specific mortality for all ages separately for the 7 Mediterranean and the 8 North-Central European cities. As shown, the effects for total, cardiovascular disease, and cerebrovascular mortality were higher in Mediterranean cities, but the inverse was true for respiratory causes of death. Heterogeneity remained significant for respiratory mortality and for total mortality in only the NorthCentral cities.

Table 5 shows the cumulative effects for 30 days of apparent temperature on cause-specific daily deaths. The effect over 30 days increased by about $8 \%-13 \%$ for all-age deaths and deaths of those older than age 75 years for all, cardiovascular disease, and cerebrovascular causes, whereas it increased about $35 \%$ for respiratory causes, indicating stronger prolonged effects. The cumulative effect was smaller in the younger age groups except for respiratory causes, where a pronounced prolonged effect was observed.

Figure 6 shows the meta-analytic distributed lag curves. An effect until about day 23 was observed for all causes and was stronger for respiratory mortality. No mortality displacement was observed. 


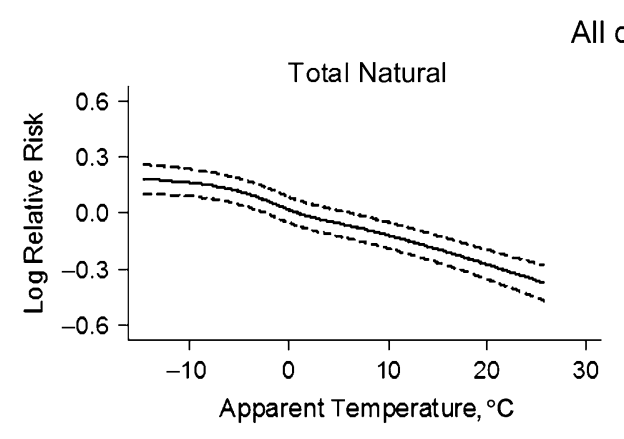

All cities
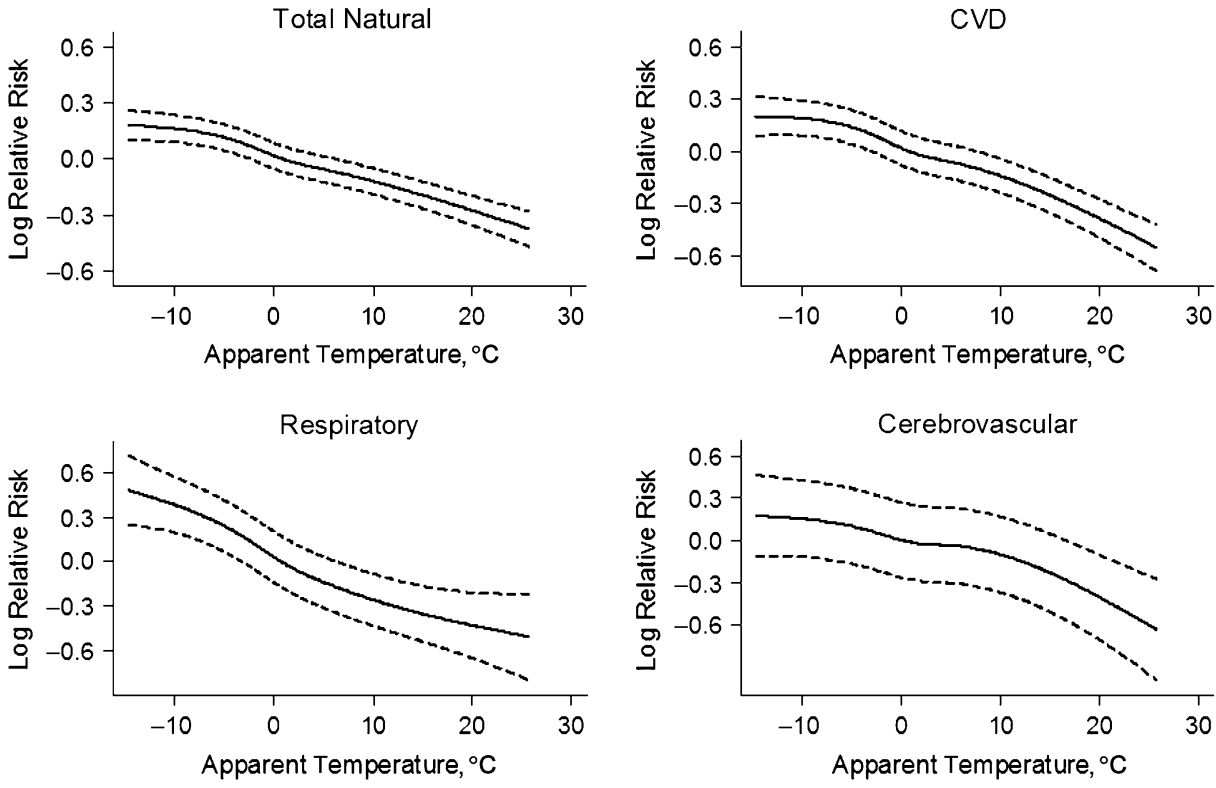

Figure 1. Combined (all 15 European cities studied) exposure-response curve (dashed lines: $95 \%$ confidence bands) of minimum apparent temperature (lags 0-15) and daily number of total natural, cardiovascular disease (CVD), respiratory, and cerebrovascular deaths, all ages, during the cold season (October-March), 1990-2000.

Table 6 shows the results from second-stage regression models and the explained heterogeneity from introducing potential effect-modifying variables in the model. All variables tested, except longitude, explained more than $10 \%$ of the heterogeneity of the effect estimates on total mortality. Humidity explained less than $10 \%$ of the heterogeneity of respiratory and cerebrovascular effect estimates. Latitude was not important for respiratory mortality effects. Mean

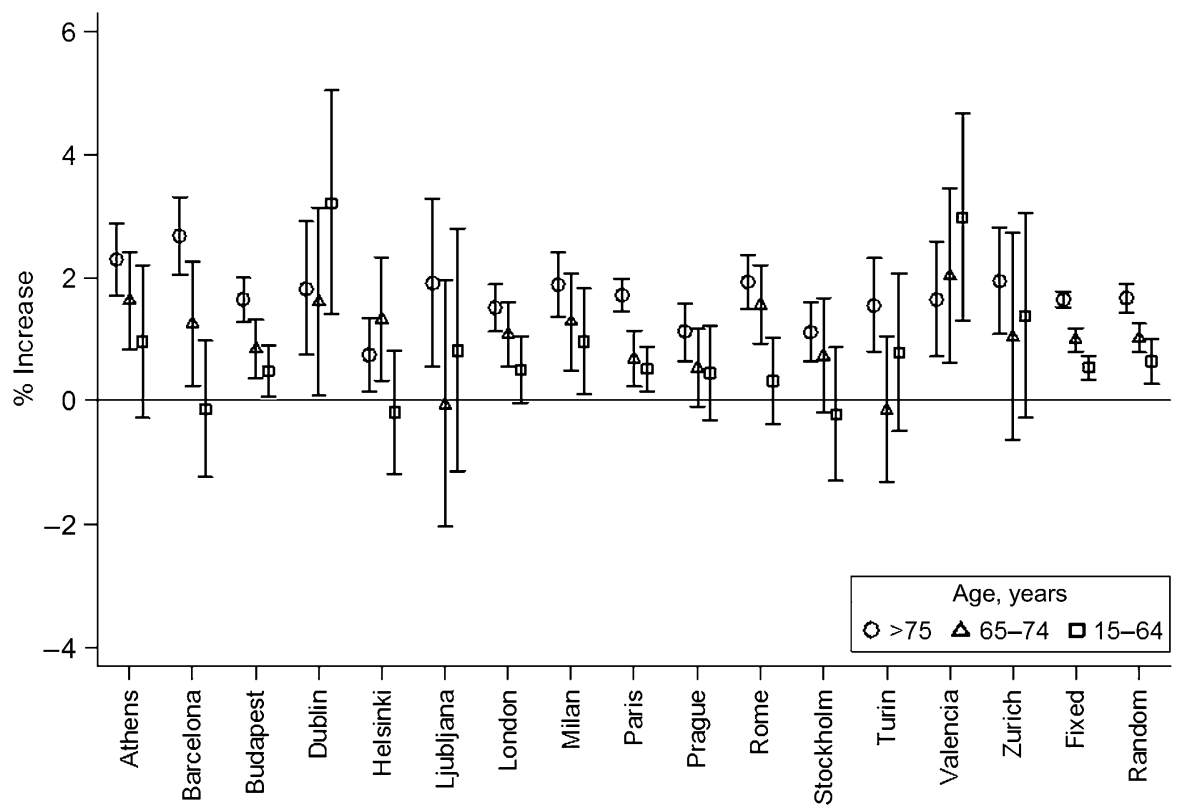

Figure 2. City-specific and pooled percentage increase (vertical lines: $95 \%$ confidence intervals) in total natural mortality for groups $>75,65-74$, and 15-64 years of age associated with a $1^{\circ} \mathrm{C}$ decrease in minimum apparent temperature (average of lags $0-15$ ), adjusting for barometric pressure, wind speed, day of the week, holiday, calendar month, and time trend during the cold season (October-March), Europe, 1990-2000. 


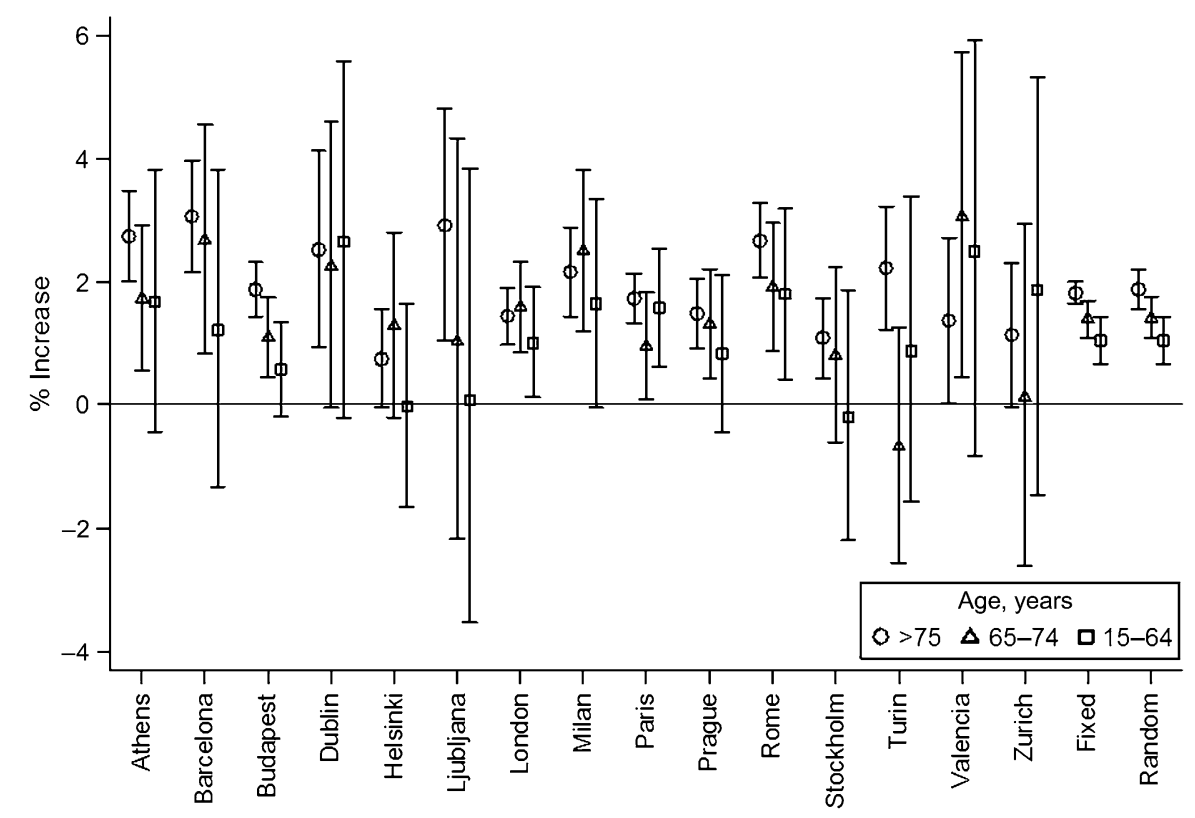

Figure 3. City-specific and pooled percentage increase (vertical lines: $95 \%$ confidence intervals) in cardiovascular disease mortality for groups $>75,65-74$, and $15-64$ years of age associated with a $1^{\circ} \mathrm{C}$ decrease in minimum apparent temperature (average of lags $0-15$ ), adjusting for barometric pressure, wind speed, day of the week, holiday, calendar month, and time trend during the cold season (October-March), Europe, 1990-2000.

temperature and mean apparent temperature had a very similar role in modifying the effects of daily apparent temperature on mortality: for total mortality and for each cause, in cities with warmer climates, the effect size was larger. The remaining heterogeneity for total mortality was not signifi- cant. Thus, the difference in mean temperature explained the heterogeneity observed in the effect estimates on total mortality. The other variables could also explain a significant, but not as high percentage of the heterogeneity, and, in most cases, significant heterogeneity remained. For

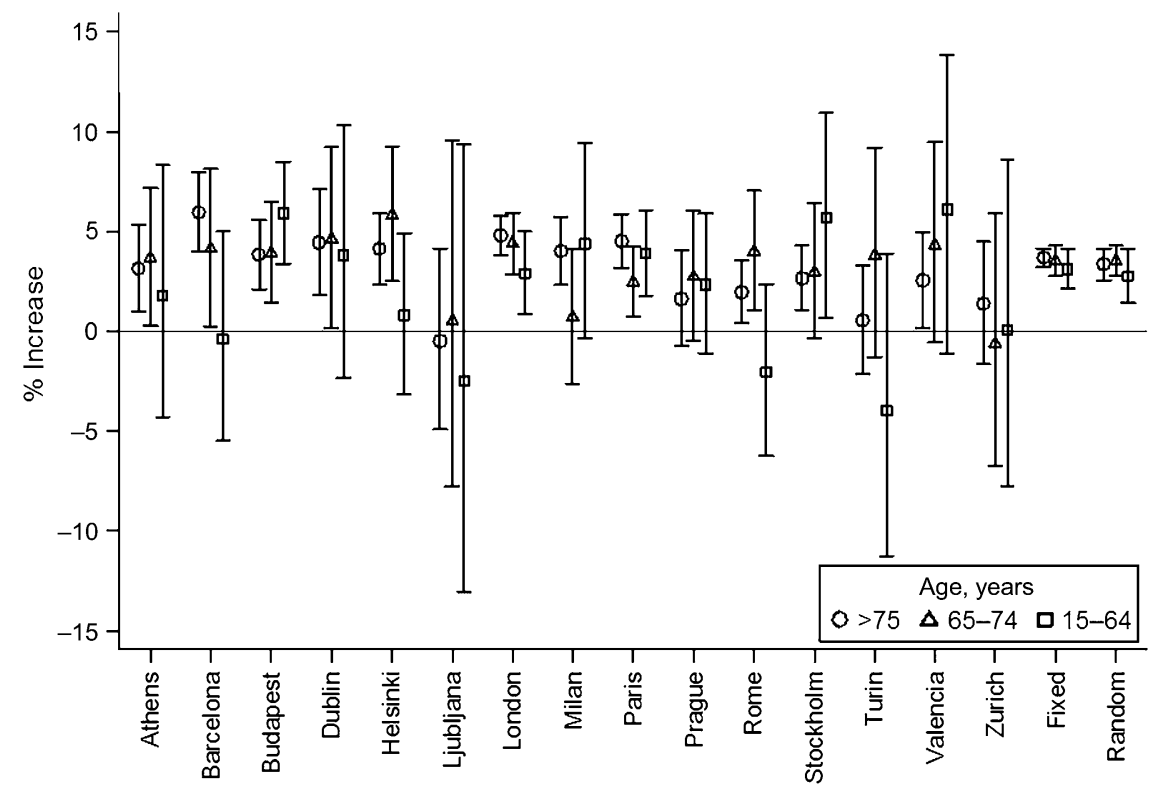

Figure 4. City-specific and pooled percentage increase (vertical lines: $95 \%$ confidence intervals) in respiratory mortality for groups $>75$, $65-74$, and 15-64 years of age associated with a $1^{\circ} \mathrm{C}$ decrease in minimum apparent temperature (average of lags $0-15$ ), adjusting for barometric pressure, wind speed, day of the week, holiday, calendar month, and time trend during the cold season (October-March), Europe, 1990-2000. 


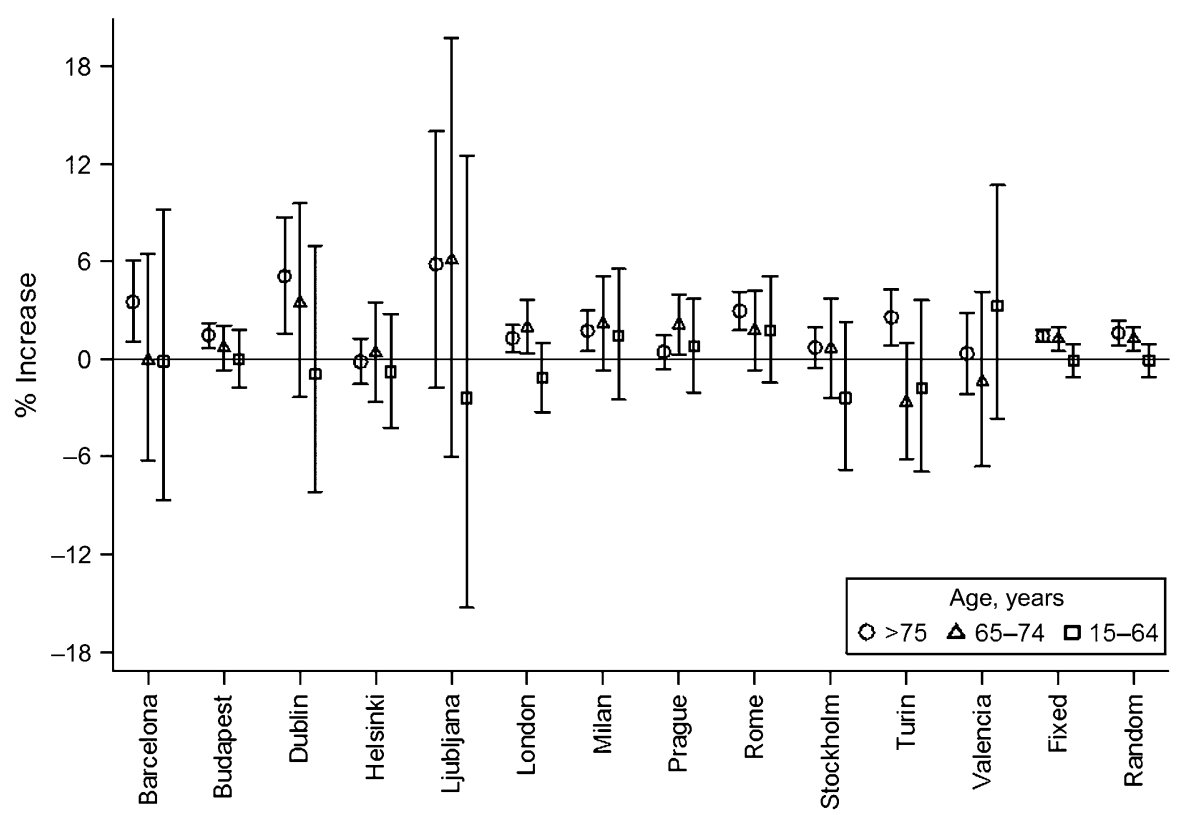

Figure 5. City-specific and pooled percentage increase (vertical lines: $95 \%$ confidence intervals) in cerebrovascular mortality for European study subjects $>75,65-74$, and $15-64$ years of age associated with a $1^{\circ} \mathrm{C}$ decrease in minimum apparent temperature (average of lags $0-15$ ), adjusting for barometric pressure, wind speed, day of the week, holiday, calendar month, and time trend during the cold season (October-March), 1990-2000.

cities with smaller variability in temperature, we observed larger effects. In addition, in less humid cities and in cities at a lower latitude (more southern), we observed larger effects on all causes. We also tested whether there was effect modification by nitrogen dioxide levels, but none was observed.

\section{DISCUSSION}

The results of the present study are based on one of the most extensive data sets used thus far in Europe to assess weather-related effects, and they are consistent with previous single-area and multicity results from Europe and the

Table 3. Percentage Increase (95\% Confidence Interval) in Daily Number of Deaths for a $1^{\circ} \mathrm{C}$ Decrease in Minimum Apparent Temperature (Average of Lags 0-15) $)^{\text {a }}$ During the Cold Season (October-March), by Cause of Death and Age Group (Years) in 15 European Cities, 1990-2000

\begin{tabular}{|c|c|c|c|c|c|c|c|c|c|c|}
\hline & \multicolumn{2}{|c|}{ All Ages } & \multicolumn{2}{|c|}{$>75$} & \multicolumn{2}{|c|}{$65-74$} & \multicolumn{2}{|c|}{$15-64$} & \multicolumn{2}{|c|}{$0-14$} \\
\hline & Increase & $95 \% \mathrm{Cl}$ & Increase & $95 \% \mathrm{Cl}$ & Increase & $95 \% \mathrm{Cl}$ & Increase & $95 \% \mathrm{Cl}$ & Increase & $95 \% \mathrm{Cl}$ \\
\hline \multicolumn{11}{|l|}{ Total natural mortality } \\
\hline Fixed pooled estimate & $1.30^{\mathrm{b}}$ & $1.20,1.40$ & $1.66^{b}$ & $1.53,1.79$ & 1.00 & $0.80,1.19$ & $0.54^{b}$ & $0.35,0.74$ & 1.16 & $0.21,2.12$ \\
\hline Random pooled estimate & 1.35 & $1.16,1.53$ & 1.67 & $1.45,1.90$ & 1.02 & $0.78,1.26$ & 0.65 & $0.28,1.02$ & 1.00 & $-0.41,2.43$ \\
\hline \multicolumn{11}{|c|}{ Cardiovascular disease mortality } \\
\hline Fixed pooled estimate & $1.66^{\mathrm{b}}$ & $1.52,1.81$ & $1.83^{b}$ & $1.66,2.00$ & 1.40 & $1.10,1.71$ & 1.05 & $0.67,1.43$ & & \\
\hline Random pooled estimate & 1.72 & $1.44,2.01$ & 1.89 & $1.56,2.21$ & 1.42 & $1.09,1.76$ & 1.05 & $0.67,1.43$ & & \\
\hline \multicolumn{11}{|l|}{ Respiratory mortality } \\
\hline Fixed pooled estimate & $3.60^{b}$ & $3.22,3.99$ & $3.68^{b}$ & $3.21,4.15$ & 3.53 & $2.76,4.31$ & 3.11 & $2.13,4.10$ & & \\
\hline Random pooled estimate & 3.30 & $2.61,3.99$ & 3.34 & $2.56,4.13$ & 3.53 & $2.76,4.31$ & 2.76 & $1.42,4.12$ & & \\
\hline \multicolumn{11}{|l|}{ Cerebrovascular mortality } \\
\hline Fixed pooled estimate & $1.20^{\mathrm{b}}$ & $0.89,1.52$ & $1.41^{\mathrm{b}}$ & $1.04,1.78$ & 1.23 & $0.50,1.96$ & -0.09 & $-1.06,0.89$ & & \\
\hline Random pooled estimate & 1.25 & $0.77,1.73$ & 1.58 & $0.84,2.33$ & 1.23 & $0.50,1.96$ & -0.09 & $-1.06,0.89$ & & \\
\hline
\end{tabular}

Abbreviation: $\mathrm{Cl}$, confidence interval.

${ }^{a}$ Adjusting for barometric pressure, wind speed, day of the week, holiday, calendar month, and time trend.

${ }^{b}$ Significant heterogeneity. 
Table 4. Percentage Increase (95\% Confidence Interval) in Daily Number of Deaths for All Age Groups in 7 Mediterranean and 8 North-Central European Cities for a $1^{\circ} \mathrm{C}$ Decrease in Minimum Apparent Temperature (Average of Lags 0-15) During the Cold Season (October-March), by Cause of Death, 1990-2000

\begin{tabular}{|c|c|c|c|c|}
\hline & \multicolumn{2}{|c|}{ Mediterranean } & \multicolumn{2}{|c|}{ North-Central } \\
\hline & Increase & $95 \% \mathrm{Cl}$ & Increase & $95 \% \mathrm{Cl}$ \\
\hline \multicolumn{5}{|l|}{ Total natural mortality } \\
\hline Fixed pooled estimate & 1.62 & $1.44,1.80$ & $1.16^{\mathrm{a}}$ & $1.04,1.28$ \\
\hline Random pooled estimate & 1.62 & $1.38,1.85$ & 1.15 & $0.96,1.34$ \\
\hline \multicolumn{5}{|c|}{ Cardiovascular disease mortality } \\
\hline Fixed pooled estimate & 2.29 & $2.02,2.56$ & 1.41 & $1.24,1.58$ \\
\hline Random pooled estimate & 2.29 & $2.01,2.57$ & 1.38 & $1.16,1.61$ \\
\hline \multicolumn{5}{|l|}{ Respiratory mortality } \\
\hline Fixed pooled estimate & $2.98^{\mathrm{a}}$ & $2.28,3.68$ & $3.87^{a}$ & $3.41,4.33$ \\
\hline Random pooled estimate & 2.80 & $1.62,4.01$ & 3.66 & $2.87,4.45$ \\
\hline \multicolumn{5}{|l|}{ Cerebrovascular mortality } \\
\hline Fixed pooled estimate & 2.05 & $1.44,2.66$ & 0.89 & $0.52,1.26$ \\
\hline Random pooled estimate & 2.03 & $1.36,2.69$ & 0.89 & $0.52,1.26$ \\
\hline
\end{tabular}

Abbreviation: $\mathrm{Cl}$, confidence interval.

a Significant heterogeneity.

United States. The effects of apparent temperature on daily mortality were investigated separately for the cold (October-March) and the warm (April-September) seasons. This design provided flexibility in the analysis because it reduced the complexity of the control for temporal confounding, avoiding the use of smooth functions when controlling for time trend. It also enabled use of different model structures per season.
We confirmed that temperature in the cold season is inversely associated with mortality and that, in warmer (southern) cities, the cold-temperature effect is higher. This finding is consistent with previously reported results from the United States and Europe (5-8). One study performed in the coldest setting, in Siberia, actually found no cold-related mortality (29). In a study of 14 European countries, Healy (8) found the highest rates of excess winter mortality in

Table 5. Cumulative Effect of Apparent Temperature on Mortality From Polynomial Distributed Lags Models: Percentage Increase (95\% Confidence Interval) in Daily Number of Deaths for a $1^{\circ} \mathrm{C}$ Decrease in Minimum Apparent Temperature Over 30 Days During the Cold Season (October-March), by Cause of Death and Age Group (Years) in 15 European Cities, 1990-2000

\begin{tabular}{|c|c|c|c|c|c|c|c|c|c|c|}
\hline & \multicolumn{2}{|c|}{ All Ages } & \multicolumn{2}{|c|}{$>75$} & \multicolumn{2}{|c|}{$65-74$} & \multicolumn{2}{|c|}{$15-64$} & \multicolumn{2}{|c|}{$0-14$} \\
\hline & Increase & $95 \% \mathrm{Cl}$ & Increase & $95 \% \mathrm{Cl}$ & Increase & $95 \% \mathrm{Cl}$ & Increase & $95 \% \mathrm{Cl}$ & Increase & $95 \% \mathrm{Cl}$ \\
\hline \multicolumn{11}{|l|}{ Total natural mortality } \\
\hline Random pooled estimate & 1.44 & $1.22,1.66$ & 1.84 & $1.55,2.13$ & 1.11 & $0.84,1.37$ & 0.51 & $-0.00,1.03$ & 0.80 & $-1.04,2.68$ \\
\hline \multicolumn{11}{|c|}{ Cardiovascular disease mortality } \\
\hline Fixed pooled estimate & $1.85^{\mathrm{a}}$ & $1.67,2.03$ & $2.05^{a}$ & $1.84,2.27$ & 1.70 & $1.33,2.07$ & 0.93 & $0.45,1.42$ & & \\
\hline \multicolumn{11}{|l|}{ Respiratory mortality } \\
\hline Fixed pooled estimate & $4.98^{\mathrm{a}}$ & $4.50,5.45$ & $4.95^{\mathrm{a}}$ & $4.36,5.54$ & 4.94 & $3.94,5.95$ & $4.08^{\mathrm{a}}$ & $2.82,5.36$ & & \\
\hline Random pooled estimate & 4.40 & $3.35,5.45$ & 4.38 & $3.29,5.48$ & 4.94 & $3.94,5.95$ & 3.33 & $1.37,5.32$ & & \\
\hline \multicolumn{11}{|l|}{ Cerebrovascular mortality } \\
\hline Fixed pooled estimate & $1.21^{\mathrm{a}}$ & $0.81,1.61$ & $1.52^{\mathrm{a}}$ & $1.05,1.99$ & $1.07^{\mathrm{a}}$ & $0.14,2.01$ & -0.35 & $-1.54,0.86$ & & \\
\hline
\end{tabular}

Abbreviation: $\mathrm{Cl}$, confidence interval.

a Significant heterogeneity. 

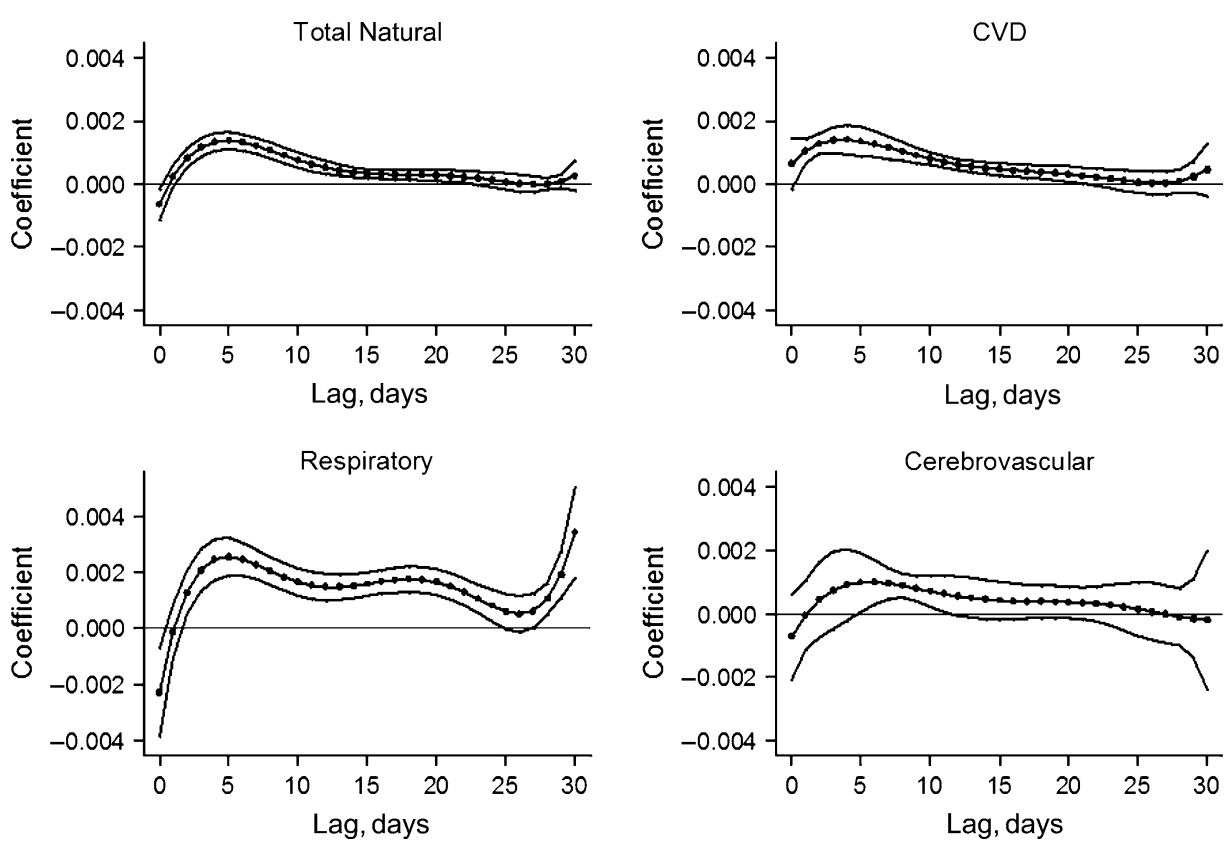

Figure 6. Combined (all 15 European cities studied) distributed lags curves (and $95 \%$ confidence intervals) up to 30 days of the effect of a $1{ }^{\circ} \mathrm{C}$ lower apparent temperature on daily number of deaths, all ages, during the cold season (October-March), 1990-2000. CVD, cardiovascular disease.

southern countries. The Eurowinter study found that the effect of cold was larger in warmer countries for respiratory causes, but this effect was not so pronounced for cardiovascular disease and ischemic heart disease (7). In a US multicity study, Braga et al. (5) observed stronger effects of cold weather on cardiovascular disease compared with respiratory mortality, especially in colder cities. On the contrary, O'Neill et al. (30) found, in Chicago, Illinois, that the effect of cold was stronger on respiratory mortality. Curriero et al. (6) grouped cardiovascular disease and respiratory deaths together and observed effects similar to those on total mortality.

Some studies focused on cardiac mortality because there is a stronger a priori hypothesis that cold specifically affects the cardiovascular system. Keatinge $(31,32)$ studied the effects of cold exposure on the metabolic and vascular responses and also investigated acclimatization and its potential modifying role. In another study, Keatinge et al. (33) showed that cold exposure increased platelet and red cell counts, blood viscosity, and arterial pressure.

In this study, we observed larger effects on deaths from respiratory causes. Furthermore, when more prolonged effects were studied with distributed lag models, it appears that the respiratory effects are more persistent through time. From the observed lagged effects, it seems that the cold effect starts on lag 1 . To explore whether the polynomial constraint forced the shape of the curve at lag 0 (same-day effect), we tried an alternative analysis, excluding lag 0 from the model; the shape remained identical after day 2 , while the effect on day 1 increased somewhat. Findings are consistent with those reported by Goodman et al. (22).
We also investigated the effects by age groups. For all outcomes, the effects had an increasing gradient with age: they could be observed in the younger age groups, but the effects were clearly larger in the elderly. This observation is not entirely consistent with other reports. O' Neill et al. (30) found stronger cold-related effects on mortality for those younger than age 65 years, and Curriero et al. (6) reported a qualitatively similar relation between weather and mortality in the same age groups found in the present study. In general, reports in Europe show that the elderly are more sensitive $(23,34,35)$.

We observed significant heterogeneity in the effect estimates from specific cities, which may be due to differences in environmental, socioeconomic, and behavioral patterns. Heterogeneity was reduced after dividing the cities into 2 groups according to geographic location, with the objective of having more homogeneous groups. In second-stage models, we identified various climatic effect modifiers that reduced the heterogeneity substantially or eliminated it. We identified mean winter temperature over the study period as the most important effect modifier of the association between apparent temperature and mortality (higher temperature was associated with larger cold effects). We also tested 2 measures of temperature variability and found that, in cities with greater temperature variability, the observed effects were smaller. This finding does not agree with that of Braga et al. (5), who found that more variability was associated with larger effects. Mean relative humidity could explain a substantial percentage of the heterogeneity of the effects on only total and cardiovascular disease mortality. Latitude provided results consistent with the finding of 


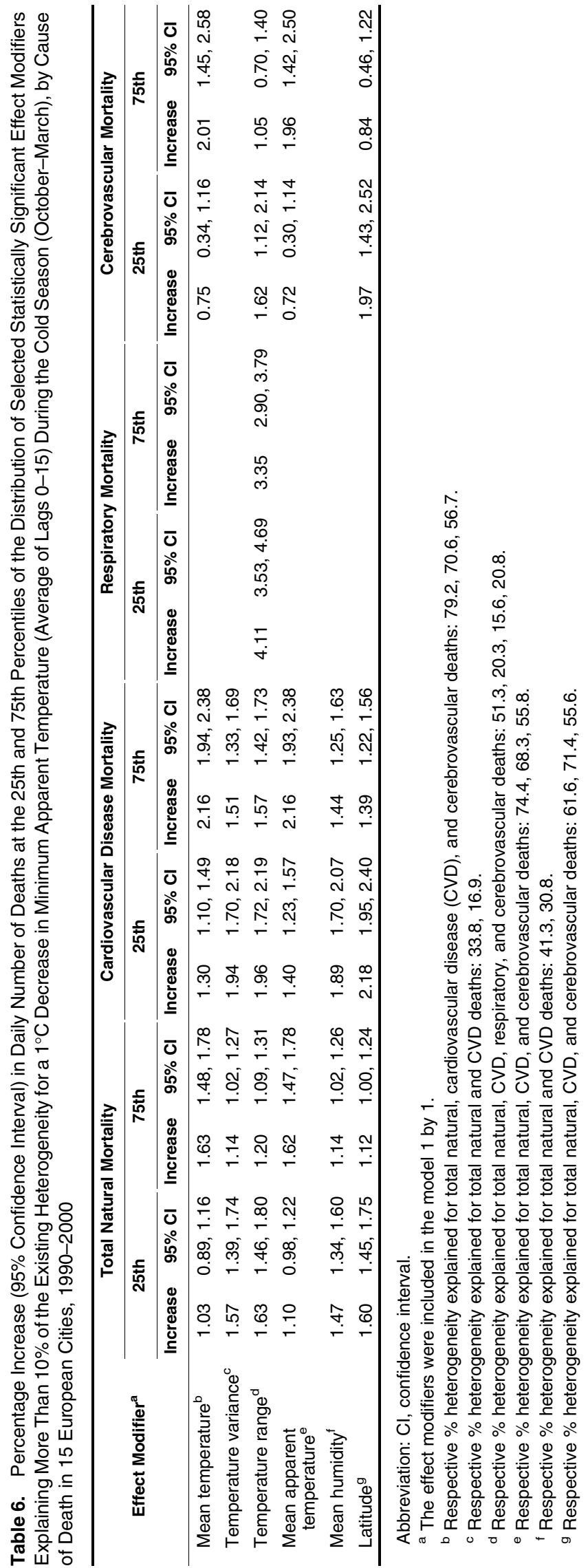

the effect-modifying role of temperature. Even though total mortality was recorded completely in all the cities included in this study, there might be variable, nondifferential misclassification errors in the coding of cause of death. This issue could not be addressed in the present study and may be a factor contributing to the observed heterogeneity.

Other studies have also attempted to investigate effect modification. Wilkinson et al. $(36,37)$ studied potential effect modifiers of cold-related mortality in the elderly in Great Britain and identified female sex and preexisting respiratory illness. In a US study of 7 cities, O'Neill et al. (30) found that deaths among blacks compared with whites, among the less educated, and outside the hospital were more strongly associated with cold temperatures but that gender made no difference. In an ecologic analysis comparing monthly mortality in 14 European counties, Healy (8) identified several environmental and socioeconomic factors associated with the magnitude of effects. Thus, higher mean temperatures and, to a lesser extent, higher humidity are associated with greater cold-related mortality. Furthermore, countries with greater poverty, inequality, and deprivation appear to have more excess winter mortality. More research is needed to estimate the independent role of each climate, community, and individual factor on the cold-related mortality effect. New approaches integrating area-level variables as well as individual-level ones are necessary (38).

In the present work, we selected apparent temperature as the weather index because it is now used by various public health agencies to predict discomfort conditions. Apparent temperature is calculated on the basis of temperature and humidity (or dew point) and is supposed to take into account the "discomfort" felt by the population from a combination of temperature and humidity conditions $(14,39)$. It is not clear which is the best indicator to use when assessing temperature effects. An alternative would be to use temperature and a measure of humidity separately. This latter possibility provides more flexibility in estimating the separate temperature and humidity effects on the studied health index. Studies that have assessed these 2 factors separately show that humidity plays a small and inconsistent role in affecting mortality (5). This issue deserves further investigation.

Concluding, we described the association between cold weather and mortality in 15 European cities covering a wide range of climatic, sociodemographic, cultural, and health characteristics. Our results add evidence that cold-related mortality is an important public health problem across Europe and should not be overlooked by public health authorities because of the recent focus on heat-wave episodes.

\section{ACKNOWLEDGMENTS}

Author affiliations: Department of Hygiene, Epidemiology and Medical Statistics, Medical School, University of Athens, Athens, Greece (A. Analitis, K. Katsouyanni); Department of Statistics G. Parenti, University of Florence, Florence, Italy (A. Biggeri, M. Baccini); Department of Public Health and Clinical Medicine, University of Umeå, Umeå, Sweden (B. Forsberg); Epidemiology Unit, Milan 
Local Health Authority, Milan, Italy (L. Bisanti); Department of Epidemiology Local Health Authority Roma E, Rome, Italy (U. Kirchmayer, P. Michelozzi); Valencian School of Health Studies (EVES) and CIBER in Epidemiology and Public Health (CIBERESP), Valencia, Spain (F. Ballester); Environmental Epidemiology Unit, Regional Agency for Environmental Protection, Piedmont Region, Grugliasco, Italy (E. Cadum); School of Physics, Dublin Institute of Technology, Dublin, Ireland (P. G. Goodman); Department of Environmental Health, Institute of Public Health, Ljubljana, Slovenia (A. Hojs); Municipal Institute for Medical Research (IMIM), Barcelona, Spain (J. Sunyer); and Unit of Environmental Epidemiology, National Public Health Institute, Kuopio, Finland (P. Tiittanen).

This study was funded by the European Commission, DG Research, FP5 (contract QLK4-CT-2001-00152).

The PHEWE Collaborative Group: Department of Epidemiology, Local Health Authority RM/E, Rome, Italy: P. Michelozzi, U. Kirchmayer, F. de'Donato, M. D’Ovidio, D. D'Ippoliti, and C. Marino; School of Geography, Geology and Environmental Science, University of Auckland, Auckland, New Zealand: G. McGregor; Department of Statistics, University of Florence, Florence, Italy: A. Biggeri and M. Baccini; Biostatistics Unit, Institute for Cancer Prevention (CSPO), Florence, Italy: G. Accetta; WHO-Regional Office for Europe, Rome, Italy: B. Menne and T. Kosatsky; Department of Hygiene \& Epidemiology, University of Athens Medical School, Athens, Greece: K. Katsouyanni and A. Analitis; Department of Astrogeophysics, University of Joannina, Joannina, Greece: P. Kassomenos; Municipal Medical Research Institute, Barcelona, Spain: J. Sunyer; Division of Community Health Sciences, St. George's, University of London, United Kingdom: H. R. Anderson and R. Atkinson; National Institute for Public Health Surveillance, Saint Maurice, France: S. Medina; National Centre of Public Health, Institute of Environmental Health, Budapest, Hungary: A. Paldy; Department of Epidemiology, Health Authority Milan, Milan, Italy: L. Bisanti; Regional Environmental Protection Agency of Piedmont, Grugliasco, Italy: E. Cadum; Department of Epidemiology, Charles University, Prague, Czech Republic: B. Kriz; Department of Environmental Health, Institute of Public Health, Ljubljana, Slovenia: A. Hojs; St. James's Hospital, Dublin, Ireland: L. Clancy and P. Goodman; Department of Environmental Health, Umea University, Umea, Sweden: B. Forsberg; Unit of Environmental Epidemiology, National Public Health Institute, Kuopio, Finland: J. Pekkanen; Department of Medical Statistics, National Institute of Hygiene, Warsaw, Poland: B. Woityniak; Department of Mathematical Sciences, University of Aberdeen, Aberdeen, United Kingdom: I. Jolliffe; German Meteorology Service, Freiburg, Germany: G. Jendritzky; Department of Climatology, Institute of Geography and Spatial Organization, Warszawa, Poland: K. Blazejczyk; Institute of Atmospheric Physics, Academy of Sciences, Prague, Czech Republic: R. Huth; Climatological Department, Meteorological Office, Environmental Agency, Ljubljana, Slovenia: T. Cegnar; Institute of Social and Preventive Medicine, University of Basel, Basel, Switzerland: C. Schindler; Valencia School of Health Studies, Valencia, Spain: F. Ballester; French Meteorology Service, Roissy Charles De Gaulle, France:
G. Monceau; and Department of Geography and Regional Studies, University of Miami, Miami, Florida: L. S. Kalkstein. Conflict of interest: none declared.

\section{REFERENCES}

1. Kilbourne EM. The spectrum of illness during heat waves. Am J Prev Med. 1999;16(4):359-360.

2. Kalkstein LS, Greene JS. An evaluation of climate/mortality relationships in large U.S. cities and the possible impacts of a climate change. Environ Health Perspect. 1997;105(1): 84-93.

3. Kunst AE, Looman CW, Mackenbach JP. Outdoor air temperature and mortality in The Netherlands: a time-series analysis. Am J Epidemiol. 1993;137(3):331-341.

4. Touloumi G, Pocock SJ, Katsouyanni K, et al. Short-term effects of air pollution on daily mortality in Athens: a timeseries analysis. Int J Epidemiol. 1994;23(5):957-967.

5. Braga AL, Zanobetti A, Schwartz J. The effect of weather on respiratory and cardiovascular deaths in 12 U.S. cities. Environ Health Perspect. 2002;110(9):859-863.

6. Curriero FC, Heiner KS, Samet JM, et al. Temperature and mortality in 11 cities of the eastern United States. Am J Epidemiol. 2002;155(1):80-87.

7. Cold exposure and winter mortality from ischaemic heart disease, cerebrovascular disease, respiratory disease, and all causes in warm and cold regions of Europe. The Eurowinter Group. Lancet. 1997;349(9062):1341-1346.

8. Healy JD. Excess winter mortality in Europe: a cross country analysis identifying key risk factors. J Epidemiol Community Health. 2003;57(10):784-789.

9. Keatinge WR. Winter mortality and its causes. Int J Circumpolar Health. 2002;61(4):292-299.

10. Reichert TA, Simonsen L, Sharma A, et al. Influenza and the winter increase in mortality in the United States, 1959-1999. Am J Epidemiol. 2004;160(5):492-502.

11. Ballester F, Michelozzi P, Iñiguez C. Weather, climate, and public health. J Epidemiol Community Health. 2003;57(10): 759-760.

12. Aylin P, Morris S, Wakefield J, et al. Temperature, housing, deprivation and their relationship to excess winter mortality in Great Britain, 1986-1996. Int J Epidemiol. 2001;30(5): 1100-1108.

13. Michelozzi P, Kirchmayer U, Katsouyanni K, et al. Assessment and prevention of acute health effects of weather conditions in Europe, the PHEWE project: background, objectives, design. Environ Health. 2007;6:12.

14. Steadman RG. The assessment of sultriness. Part I: a temperature-humidity index based on human physiology and clothing science. J Appl Meteorol. 1979;18:861-873.

15. Katsouyanni K, Touloumi G, Samoli E, et al. Confounding and effect modification in the short-term effects of ambient particles on total mortality: results from 29 European cities within the APHEA2 project. Epidemiology. 2001;12(5): 521-531.

16. Samoli E, Aga E, Touloumi G, et al. Short-term effects of nitrogen dioxide on mortality: an analysis within the APHEA project. Eur Respir J. 2006;27(6):1129-1138.

17. Liang KY, Zieger SL. Longitudinal analysis using generalized linear models. Biometrika. 1986;73:13-22.

18. Schwartz J, Dockery DW. Increased mortality in Philadelphia associated with daily air pollution concentrations. Am Rev Respir Dis. 1992;145(3):600-604. 
19. Chiogna M, Gaetan CG. Mining epidemiological time series: an approach based on dynamic regression. Stat Modelling. 2005;5:309-325.

20. Pankratz A. Forecasting With Dynamic Regression Models. New York, NY: Wiley; 1991.

21. Touloumi G, Samoli E, Quenel P, et al. Short-term effects of air pollution on total and cardiovascular mortality: the confounding effect of influenza epidemics. Epidemiology. 2005; 16(1):49-57.

22. Goodman PG, Clancy L, Dockery DW. Cause-specific mortality and the extended effects of particulate pollution and temperature exposure. Environ Health Perspect. 2004;112(2): 179-185.

23. Ballester F, Corella D, Perez-Hoyos S, et al. Mortality as a function of temperature. A study in Valencia, Spain, 1991-1993. Int J Epidemiol. 1997;26(3):551-561.

24. Wood SN. Modelling and smoothing parameter estimation with multiple quadratic penalties. J R Stat Soc (B). 2000;62: 413-428.

25. Almon S. The distributed lag between capital appropriations and expenditures. Econometrica. 1965;33: 178-196.

26. Zanobetti A, Wand MP, Schwartz J, et al. Generalized additive distributed lag models: quantifying mortality displacement. Biostatistics. 2000;1(3):279-292.

27. Berkey CS, Hoaglin DC, Mosteller F, et al. A random-effects regression model for meta-analysis. Stat Med. 1995;14(4): 395-411.

28. Berkey CS, Hoaglin DC, Antczak-Bouckoms A, et al. Metaanalysis of multiple outcomes by regression with random effects. Stat Med. 1998;17(22):2537-2550.

29. Donaldson GC, Ermakov SP, Komarov YM, et al. Cold related mortalities and protection against cold in Yakutsk, eastern Siberia: observation and interview study. BMJ. 1998; 317(7164):978-982.
30. O'Neill MS, Zanobetti A, Schwartz J. Modifiers of the temperature and mortality association in seven US cities. Am J Epidemiol. 2003;157(12):1074-1082.

31. Keatinge WR. The effect of repeated daily exposure to cold and of improved physical fitness on the metabolic and vascular response to cold air. J Physiol. 1961;157:209-220.

32. Keatinge WR. The effects of subcutaneous fat and of previous exposure to cold on the body temperature, peripheral blood flow and metabolic rate of men in cold water. $J$ Physiol. 1960;153:166-178.

33. Keatinge WR, Coleshaw SR, Cotter F, et al. Increases in platelet and red cell counts, blood viscosity, and arterial pressure during mild surface cooling: factors in mortality from coronary and cerebral thrombosis in winter. $\mathrm{Br} \mathrm{Med} \mathrm{J} \mathrm{(Clin}$ Res Ed). 1984;289(6456):1405-1408.

34. Wilkinson P, Armstrong B. Housing and excess winter death from cardiovascular disease in England, 1986-1996. Report to Joseph Rowntree Foundation. London, United Kingdom: London School of Hygiene and Tropical Medicine; 2001.

35. Keatinge WR, Donaldson GC, Bucher K, et al. Winter mortality in relation to climate. Int J Circumpolar Health. 2000; 59(3-4):154-159.

36. Wilkinson P, Armstrong B. Social and environmental determinants of excess winter deaths in England, 1986-1996. Final Report. London, United Kingdom: London School of Hygiene and Tropical Medicine; 2002.

37. Wilkinson P, Pattenden S, Armstrong B, et al. Vulnerability to winter mortality in elderly people in Britain: population based study. BMJ. 2004;329(7467):647.

38. Mitchell R. Commentary: short days—-shorter lives: studying winter mortality to get solutions. Int J Epidemiol. 2001;30(5): 1116-1118.

39. Kalkstein LS, Valimont KM. An evaluation of summer discomfort in the United States using a relative climatological index. Bull Am Meteor Soc. 1986;67:842-848. 